\title{
USE OF LABAN/BARTENIEFF MOVEMENT STUDIES TO PROFILE NEONATAL MOVEMENTS: AN EXPLORATORY STUDY
}

original paper

( ) University School of Physical Education in Wroclaw

DOI: https://doi.org/10.5114/hm.2020.94195

\section{MANSOOR RAHMAN, KAVITHA RAJA}

JSS College of Physiotherapy, Mysore, India

\begin{abstract}
Purpose. Monitoring body movements in neonates can have important clinical implications, as these are early predictors of neurodevelopmental disability. The most valid analysis method applied for this purpose is general movement assessment (GMA). Performing GMA requires special training, which is often inaccessible to healthcare providers in low- and middleincome countries. Hence, this prospective exploratory study was proposed to profile movement in typical neonates to distinguish it from abnormal movements using Laban/Bartenieff Movement Studies (LBMS) framework, which has been widely used to analyse movement in a variety of situations.
\end{abstract}

Methods. Overall, 8 typical neonates were videotaped and 10 cycles of movements were sampled, which resulted in 80 units. Data saturation occurred at 5 children.

Results. The results obtained are consistent when described using LBMS language.

Conclusions. LBMS may be a feasible and viable method to interpret and document movement patterns in neonates as an alternative to other, more resource-intensive methods.

Key words: infants, neonates, newborns, movement

\section{Introduction}

Endogenously generated movements are considered to be the most complex movement pattern of the foetus, neonate, and young infant, which emerges during early foetal period and continues for 4 months of the infant phase [1]. These are characterized by variability in speed, amplitude, force, and intensity of the movement pattern [2, 3]. Monitoring these movements has been reported to be a sensitive predictor for neurodevelopmental delay.

Prechtl and colleagues, with their observations of infants, explored a special type of spontaneous movements, so-called writhing and fidgety movements, which are elicited without obvious external stimuli. This initial writhing period may be seen at pre-term to 8 weeks post-term, persisting with slow, powerful, and elliptical movements of varying speed and amplitude performed closed to the body of neonates [4]. Their complexity is enhanced by superimposed rotations on the flexion and extension of the limbs, where the overall form is fluent and elegant. The movements were coded into a form called general movement assessment (GMA).

GMA is considered to be the gold standard for early detection of neurodevelopmental delay. However, potential drawbacks such as lack of trained professionals and proprietorship etc. are challenges to its routine use in low- and middle-income countries. Hence, there is an incipient demand for a comprehensive method of movement analysis in newborns for early diagnosis of neurodevelopmental disability.

Laban/Bartenieff Movement Studies (LBMS) constitute a method and language used to describe, visualize, interpret, and document human movement. It is generally utilised by dancers, musicians, athletes, and by health professionals such as physical therapy and occupational therapy practitioners [5].

LBMS is a system that describes how, what, where, and when the movements takes place, with a focus on entire body segments and their movements, using

Correspondence address: Mansoor Rahman, JSS College of Physiotherapy, Mysore - 570004, Karnataka, India, e-mail: mansoorrahman_jsscpt@jssonline.org

Received: June 18, 2019

Accepted for publication: December 18, 2019

Citation: Rahman M, Raja K. Use of Laban/Bartenieff Movement Studies to profile neonatal movements: an exploratory study. Hum Mov. 2020;21(4):97-101; doi: https://doi.org/10.5114/hm.2020.94195. 


\section{HUMAN MOVEMENT}

M. Rahman, K. Raja, Laban/Bartenieff Movement Studies for neonatal movements

Table 1. Parts of Laban/Bartenieff movement analysis framework

\begin{tabular}{|c|c|c|c|c|c|}
\hline \multicolumn{6}{|c|}{ Movement concept } \\
\hline Body part & Space & Effort & Support & Shape & Relationship \\
\hline $\begin{array}{l}\text { Structural and } \\
\text { physical characte- } \\
\text { ristics of body } \\
\text { during movement, i.e. } \\
\text { what body parts are } \\
\text { involved and how } \\
\text { a body part moves as } \\
\text { a whole or individual }\end{array}$ & $\begin{array}{l}\text { Motion in connection } \\
\text { with the environment, } \\
\text { i.e. where the move- } \\
\text { ments occur } \\
\text { in relation to self } \\
\text { and environment }\end{array}$ & $\begin{array}{l}\text { Subtle characteristics } \\
\text { of movement with } \\
\text { respect to inner } \\
\text { intention, i.e. how } \\
\text { the movement is } \\
\text { performed with } \\
\text { respect to space }\end{array}$ & $\begin{array}{l}\text { Area where } \\
\text { the body } \\
\text { is supported }\end{array}$ & $\begin{array}{l}\text { The way the body } \\
\text { changes its shape } \\
\text { during movement }\end{array}$ & $\begin{array}{l}\text { Relationship } \\
\text { between the } \\
\text { movements }\end{array}$ \\
\hline
\end{tabular}

Table 2. Subcategories of Laban/Bartenieff movement analysis

\begin{tabular}{ll}
\hline Subcategory & \multicolumn{1}{c}{ Movement elements } \\
\hline Body & $\begin{array}{l}\text { 1. Type (includes flexion or extension; flexion is sub-classified into contraction, fold, curvilinear, } \\
\text { and separation; extension is sub-classified into elongation, unfold, uncurving, and joining) }\end{array}$ \\
& $\begin{array}{l}\text { 2. Frequency (includes steady or sporadic) } \\
\text { 3. Chronology (includes simultaneous, successive sequential, successive overlapping, and sequential } \\
\text { overlapping) }\end{array}$ \\
& 4. Side (includes face, front, or back side) \\
\hline Space & 1. Path (includes locomotor or gesture) \\
& 2. Pattern (includes clockwise/counter-clockwise, somersault, cartwheel, and unspecified) \\
& 3. Direction (includes forward/backward, upward/downward, and right/left) \\
4. Level (includes high, mid, and level)
\end{tabular}

the concept of Body, Effort, Space, and Shape theory of LBMS [6]. The main components of the LBMS framework are illustrated in Table 1 and the subcategories are presented in Table 2 .

The system described by LBMS is comprehensive and has the potential to be used as a non-invasive and non-intrusive qualitative movement analysis with minimal resources to obtain the character and quality of movement. Prior to applying it as a tool to detect abnormality, it is necessary to profile the movements in typical neonates. This explorative study aimed to incorporate the framework of LBMS to profile movement in neonates who were expected to develop normally. The hypothesis put forward in the study was as follows: neonate movement analysis using the language of LBMS will be a sensitive and adequate tool to describe neonatal movement systematically and reliably.

\section{Material and methods}

The study involved 8 neonates ( 4 boys and 4 girls) from a tertiary referral hospital who had normal Apgar score of 7 or more at 5 minutes and no maternal history indicative of neurodevelopmental risks. Each baby was video-recorded with 2 Logitech HD C920 webcams, attached to 2 separate tripods and connected to a one-window laptop (2.0 GHz processor; 4 GB RAM; 150 GB hard drive space, and USB ports) by 2 extension cords of 5-meter length. The resolution of 1080 $\times 1920$ pixels (the highest possible) was selected to achieve the desired precision [7]. The video recording was performed when the children were in a state of active wakefulness (but not crying), in supine position, wearing comfortable clothing, with arms and legs bare, at comfortable room temperature, and at least half an hour after feeding $[4,8]$. The study was continued until 
data saturation [9]. Data saturation was obtained when no new movements were identified in 5 neonates (i.e. no additional movement were collected). Overall, 10 cycles of movement per body part were sampled in each of the 8 children, which led to 80 subunits $(10$ cycles $\times$ 8 children $=80$ units) of samples. Data were analysed by using narrative description based on LBMS.

\section{Ethical approval}

The research related to human use has complied with all the relevant national regulations and institutional policies, has followed the tenets of the Declaration of Helsinki, and has been approved by the institutional research committee of JSS College of Physiotherapy.

\section{Informed consent}

Informed consent has been obtained from the parents of each neonate included in this study.

\section{Results}

The qualitative analysis of 8 neonates was conducted by observing various aspects of movement concepts based on the LBMS framework [10]. Each movement was divided into phases by using LBMS, viz the Body, Effort, and Space components. Finally, the movements analysed in various body parts were formed as a sentence to interpret the results. Thus, the movement analysis of the 8 neonates was framed as follows: 'The approach unit started from initiation of head and limb movement with the support on torso at mid-level. Head moved into fold (i.e. rotation and derotation) steadily towards face side, where as for the extremities (both upper and lower extremities) movement, the type was contraction and elongation. Path of spatial change was gestural (i.e. no change of base of support since the baby in supine position) and the pattern circumscribed clockwise and counter-clockwise for head and unspecified (i.e. no particular direction of change in movement) for the extremities. The direction of movement was right and left for head and forward-upward for extremities, with the exception of lower leg, where it was backward and forward. Throughout the movement patterns of the body parts, the frequency was considered sporadic, with the chronology of sequential overlapping for the extremities. Effort was strong and sudden throughout the movement.' These results are summarized in Table 3 and illustrated in Figures 1-3.

\section{Discussion}

We have developed and clinically tested a movement analysis of neonates using the LBMS framework, which can be applied to monitor neonate movement in clinical settings. When the movement analysed was compared with the terminology of GMA [11-14], similarities were apparent. These included the writhing movement in Prechtl's GMA, which is similar to the Space and Effort components of LBMS, i.e. the Space component (level mid to high, high to mid, and vice versa) correlates with the amplitude component of the writhing movement in Prechtl's GMA [15-17] and the Effort component (strong and sudden movement) correlates with the speed component of writhing in Prechtl's GMA [18, 19].

Using the LBMS framework gives organization to movement analysis and is superior to an informal analysis. When the initial framework was repeated

Table 3. Description of various components of neonate movements

\begin{tabular}{lcc}
\hline \multicolumn{1}{c}{ Body } & Space & Effort \\
\hline Type: & Path: & Strong and sudden \\
i) Head and face - rotation & Gesture & \\
and derotation & Pattern: \\
ii) Rest all - contraction & i) Head and face - clockwise \\
and elongation & and counter-clockwise \\
Frequency: & ii) Rest all - unspecified \\
Sporadic & Direction: \\
Chronology: & i) Head and face - right and left \\
Sequential overlapping except head & ii) Rest all - forward and upward \\
and face & except lower leg, which was & \\
& backward and forward \\
& Level: & \\
& i) Head and face - mid \\
& ii) Upper and lower extremity - \\
mid to high and high to mid
\end{tabular}




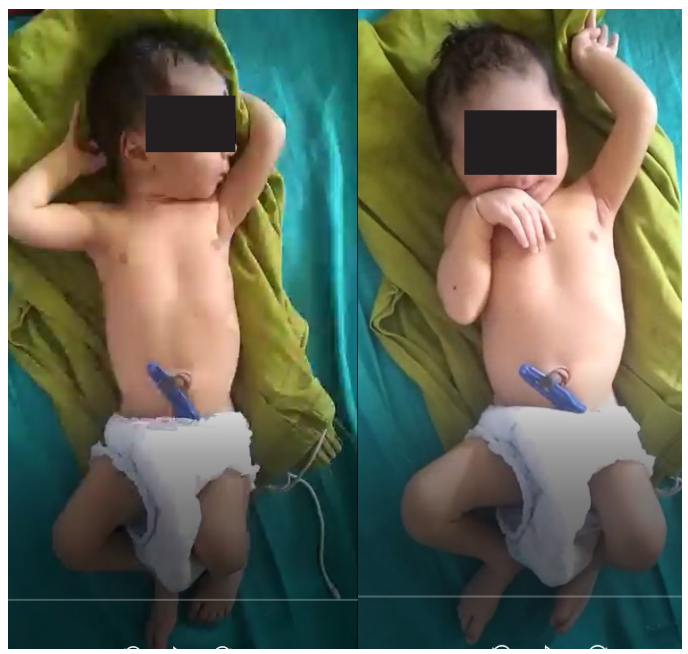

Figure 1. The approach unit where the head moved into fold, i.e. rotation and derotation towards the left side

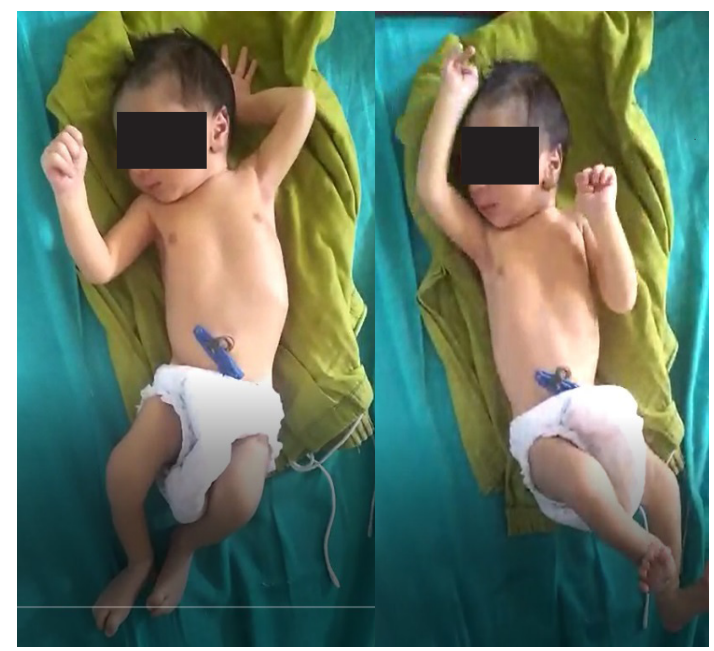

Figure 2. The approach unit where the movement type in upper extremity was contraction and elongation (right side)

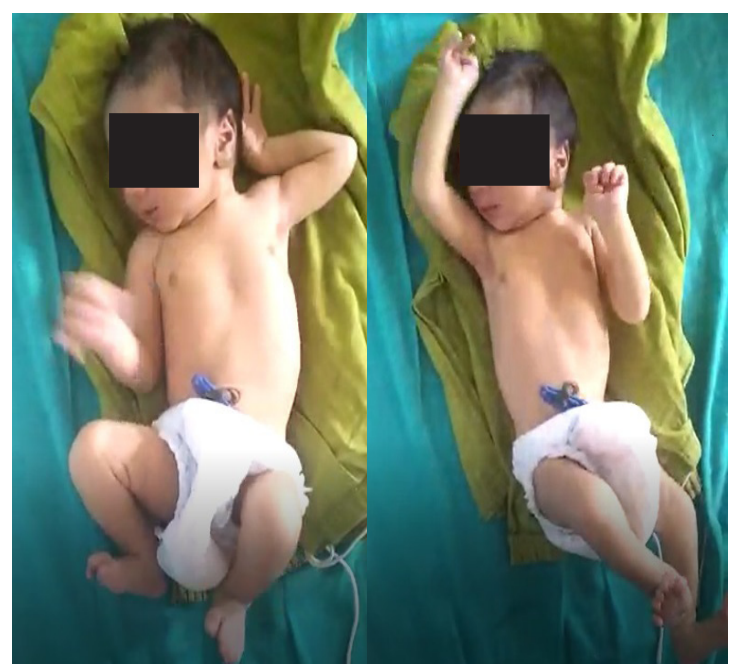

Figure 3. The approach unit where the movement type in lower extremity was contraction and elongation (right side) on random sections of the recorded videos, there was complete agreement of the results. This underlines the fact that the framework is clear and easy to use.

The strengths of this study are as follows:

1 . As video recording was performed, the movements could be observed repeatedly to avoid flaws or errors in the analysis.

2. The method of movement analysis does not have proprietorship and can be learned under the tutorship of trained LBMS professionals. Hence, it might be a feasible tool and can be applied by all healthcare professionals who work with movement analysis of neonates.

In turn, the limitations and future recommendations are provided below:

1. This is a preliminary study and the results must be confirmed in a larger group of neonates. Inter-rater agreement must be established and validation in a longitudinal study is required.

2. The Shape component of LBMS was not considered for this study. Future research should incorporate this component to include preliminary understanding of Shape since a large part of neonatal movements includes Shape and inner referential movements.

3. This study should be further validated by professionals trained in the LBMS framework for appropriate use of the LBMS language.

\section{Conclusions}

This was an exploratory study and hence firm conclusions cannot be drawn. But from the above results it is clear that the movement analysis using the LBMS framework may be a viable method to detect and describe movement in neonates. Since GMA is considered as the gold standard for early identification of neurodevelopmental delay, the method described here must be validated against GMA. As the primary focus of this study was to explore the possibility of LBMS application in profiling neonatal movement and in early identification of neurodevelopmental disability, the terminology used has been restricted to common language without technical LBMS terminology.

\section{Acknowledgments}

The authors express their sincere gratitude to Dr. Srilatha Girish PT PhD, who assisted us with Laban terminology and usage.

\section{Disclosure statement}

No author has any financial interest or received any financial benefit from this research. 


\section{Conflict of interest}

The authors state no conflict of interest.

\section{References}

1. Prechtl HF, Fargel JW, Weinmann HM, Bakker HH. Postures, motility and respiration of low-risk pre-term infants. Dev Med Child Neurol. 1979;21(1):3-27; doi: 10.1111/j.1469-8749.1979.tb01577.x.

2. Prechtl HF. Qualitative changes of spontaneous movements in fetus and preterm infant are a marker of neurological dysfunction. Early Hum Dev. 1990;23(3):151158; doi: 10.1016/0378-3782(90)90011-7.

3. Prechtl HF, Einspieler C, Cioni G, Bos AF, Ferrari F, Sontheimer D. An early marker for neurological deficits after perinatal brain lesions. Lancet. 1997;349(9062): 1361-1363; doi: 10.1016/S0140-6736(96)10182-3.

4. Zuk L, Harel S, Leitner Y, Fattal-Valevski A. Neonatal general movements: an early predictor for neurodevelopmental outcome in infants with intrauterine growth retardation. J Child Neurol. 2004;19(1):14-18; doi: 10.1177/088307380401900103011.

5. Guest AH. Labanotation: the system of analyzing and recording movement. New York: Routledge; 2013.

6. Schwartz P. Laban movement analysis: theory and application. J Phys Educ Recreat Dance. 1995;66(2): 25-26; doi: 10.1080/07303084.1995.10607037.

7. HD Pro Webcam C920 - Logitech Support: Logitech; 2012. Available from: https://support.logitech.com/ en_us/product/hd-pro-webcam-c920.

8. Ricci E, Einspieler C, Craig AK. Feasibility of using the general movements assessment of infants in the United States. Phys Occup Ther Pediatr. 2018;38(3):269279; doi: 10.1080/01942638.2017.1395380.

9. Saunders B, Sim J, Kingstone T, Baker S, Waterfield J, Bartlam B, et al. Saturation in qualitative research: exploring its conceptualization and operationalization. Qual Quant. 2018;52(4):1893-1907; doi: 10.1007/ s11135-017-0574-8.

10. Groff E. Laban movement analysis: charting the ineffable domain of human movement. J Phys Educ Recreat Dance.1995;66(2):27-30;doi:10.1080/07303084.1995. 10607038.

11. Einspieler C, Prechtl HFR. Prechtl's assessment of general movements: a diagnostic tool for the functional assessment of the young nervous system. Ment Retard Dev Disabil Res Rev. 2005;11(1):61-67; doi: 10.1002/ mrdd.20051.

12. Einspieler C, Prechtl HFR, Bos A, Ferrari F, Cioni G. Prechtl's method on the qualitative assessment of general movements in preterm, term and young infants. London: Mac Keith Press; 2004.

13. Einspieler C, Sigafoos J, Bartl-Pokorny KD, Landa R, Marschik PB, Bölte S. Highlighting the first 5 months of life: general movements in infants later diagnosed with autism spectrum disorder or Rett syndrome. Res Autism Spectr Disord. 2014;8(3):286-291; doi: 10.1016/ j.rasd.2013.12.013.
14. Kodric J, Sustersic B, Paro-Panjan D. Assessment of general movements and 2.5 year developmental outcomes: pilot results in a diverse preterm group. Eur J Paediatr Neurol. 2010;14(2):131-137; doi: 10.1016/j. ejpn.2009.04.012.

15. Prechtl HF, Ferrari F, Cioni G. Predictive value of general movements in asphyxiated fullterm infants. Early Hum Dev. 1993;35(2):91-120; doi: 10.1016/0378-3782(93) 90096-d.

16. Prechtl HF. The optimality concept. Early Hum Dev. 1980;4(3):201-205; doi: 10.1016/0378-3782(80)90026-2.

17. Hadders-Algra M. General movements in early infancy: what do they tell us about the nervous system? Early Hum Dev. 1993;34(1-2):29-37; doi: 10.1016/03783782(93)90038-v.

18. Adde L. Prediction of cerebral palsy in young infants: computer-based assessment of general movements. Doctoral thesis. Trondheim: Norwegian University of Science and Technology, Faculty of Medicine; 2010.

19. Cioni G, Prechtl HF, Ferrari F, Paolicelli PB, Einspieler C, Roversi MF. Which better predicts later outcome in full-term infants: quality of general movements or neurological examination? Early Hum Dev. 1997;50(1): 71-85; doi: 10.1016/s0378-3782(97)00094-7. 